\title{
Atenolol eye drops in glaucoma: a double-masked, controlled study
}

\author{
CALBERT I. PHILlips, ${ }^{1}$ SHEILA M. GORE, ${ }^{2}$ MARGARET J. MACDONALD, ${ }^{1}$ \\ AND PATRICIA M. CULLEN ${ }^{1}$ \\ ${ }^{1}$ From the Department of Ophthalmology, University of Edinburgh and Princess Alexandra Eye Pavilion, \\ Royal Infirmary, Edinburgh; ${ }^{2}$ Department of Statistics, King's College, University of Aberdeen
}

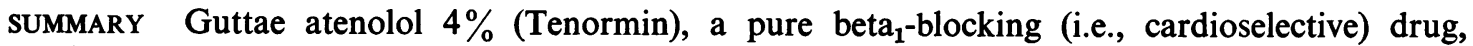
produced a median overall fall of $5.6 \mathrm{mmHg}$ (range 3.2 to $13.2 \mathrm{mmHg}$ ) in the first tonometrised eyes of 7 patients with open-angle glaucoma or ocular hypertension and 1 with closed-angle glaucoma (off any treatment for the whole of the day preceding each test day) after allowance for an 'effect' of guttae saline $0.9 \%$, in a double-masked, cross-over trial. By a Wilcoxon matched pairs rank test this was significant at the $\mathrm{P}<0.05$ level. The median overall fall of $3.5 \mathrm{mmHg}$ (range 0.8 to 10.8 $\mathrm{mmHg}$ ) in the second-tonometrised eyes of 7 patients ( 1 of the 8 contributed only 1 eye) was also significant $(\mathrm{P}<0 \cdot 05)$.

In 2 patients who had been treated with guttae atenolol $4 \%$ daily $3 \times$ for 1 and 2 months there is evidence that, on replacing the atenolol $4 \%$ with saline $0.9 \%$, a rise of pressure of around $3 \mathrm{mmHg}$ occurred 2 and 3 and 5 days later, i.e., the drug still retained its effectivity (? slightly reduced) after 1 and 2 months.

Atenolol (Tenormin) is a recently introduced betaadrenergic blocking drug which is cardioselective, i.e., blocks $\beta_{1}$ effects on the heart and lacks intrinsic sympathomimetic properties as well as membranestabilising effects (Barrett et al., 1973). Orally, it has already been shown to reduce ocular tension (Elliot et al., 1975; Wettrell and Pandolfi, 1975), as do other beta-blocking drugs.

The present trial was devised because topical treatment by drugs which reduce blood pressure seems preferable to their systemic use. There was some expectation of success because guttae propranolol 1\% (Musini et al., 1971; Vale et al., 1972), guttae practolol 10\% (Vale and Phillips, 1973), and guttae pindolol 1\% (Bonomi and Steindler, 1975) are already known to reduce ocular tension. Two preliminary studies of guttae atenolol $4 \%$ on normal volunteers were made at this hospital; one showed a small but statistically significant reduction in tension (Phillips et al., 1976). An important advantage of atenolol over propranolol is the absence of local anaesthetic effect and over practolol the absence of any evidence of serious toxic side-effects.

The aim was to assess whether guttae atenolol $4 \%$ instilled into both conjunctival sacs reduces ocular

Address for reprints: Professor C. I. Phillips, Eye Pavilion, Chalmers Street, Edinburgh EH3 9HA, Scotland tension when compared with guttae saline $0.9 \%$ in a randomised double-masked trial on 8 patients.

\section{Method}

Seven patients with open-angle glaucoma or ocular hypertension and 1 with closed-angle glaucoma were entered into the study serially. They gave informed consent to the investigation, which involved all-day attendance as outpatients on the same day in 2 consecutive weeks. Details from the patients' histories are given in Table 1.

Patients were taken off treatment on the day preceding each study day. Throughout the trial, for each patient, both eyes were treated and tonometrised systematically in the order right eye first, followed by left eye unless there were clinical contraindications. This occurred in 1 patient whose right eye was his only seeing eye, so that, although both eyes were treated, only the left was tonometrised.

Reference pressure was taken at 0900 in both eyes (with the exception of the patient described above) on both days of study just prior to administration of drops. Thereafter tonometry was done at $1 \frac{1}{2}, 3 \frac{1}{2}, 5 \frac{1}{2}$, and $7 \frac{1}{2}$ hours after treatment.

Drops were administered by the tonometrist from a bottle identified by the patient's code number and 
Table 1 Diagnoses and current treatment of patients

\begin{tabular}{|c|c|c|c|c|}
\hline $\begin{array}{l}\text { Patient } \\
\text { No. }\end{array}$ & $\begin{array}{l}\text { Age } \\
\text { (in years) }\end{array}$ & Sex & Diagnosis & Treatment \\
\hline 1 & 72 & $\mathbf{M}$ & $\begin{array}{l}\text { R. and } L \text {. open- } \\
\text { angle glaucoma }\end{array}$ & $\begin{array}{l}\text { Pilocarpine eye drops } \\
4 \% \text {, daily } 4 \times, R \text {. } \\
\text { and } L \text {. } \\
\text { Eppy eye drops } 1 \% \text {, } \\
\text { daily } 2 \times, R \text {. and } L \text {. }\end{array}$ \\
\hline \multirow[t]{2}{*}{2} & 64 & $\mathbf{M}$ & $\begin{array}{l}\text { R. open-angle } \\
\text { glaucoma }\end{array}$ & $\begin{array}{l}\text { Aged } 60 \text { Trephine } \\
\text { Aged } 63 \text { Leaking } \\
\text { bleb: conjunctival } \\
\text { flap re-made } \\
\text { Pilocarpine eye drops } \\
2 \% \text { each a.m. } \\
\text { Eppy eye drops } 1 \% \text {, } \\
\text { daily } 2 \times\end{array}$ \\
\hline & & & $\begin{array}{l}\text { L. ocular hyper- } \\
\text { tension }\end{array}$ & $\begin{array}{l}\text { Pilocarpine eye drops } \\
4 \% \text {, daily } 4 \times \\
\text { Eppy eye drops } 1 \% \\
\text { daily } 2 \times\end{array}$ \\
\hline 3 & 67 & $\mathbf{F}$ & $\begin{array}{l}\text { R. and L. open- } \\
\text { angle glaucoma }\end{array}$ & $\begin{array}{l}\text { Pilocarpine eye drops } \\
2 \% \text {, daily } 3 \times, \mathbf{R} \text {. } \\
\text { and } \mathrm{L} \text {. }\end{array}$ \\
\hline 4 & 64 & $\mathbf{F}$ & $\begin{array}{l}\mathbf{R} \text {. and } \mathbf{L} \text {. open- } \\
\text { angle glaucoma }\end{array}$ & $\begin{array}{l}\text { Pilocarpine eye drops } \\
1 \% \text {, daily } 3 \times, \mathbf{R} \text {. } \\
\text { and L. }\end{array}$ \\
\hline 5 & 62 & $\mathbf{M}$ & $\begin{array}{l}\text { R. predisposed to } \\
\text { CAG } \\
\text { L. closed-angle } \\
\text { glaucoma ( } 50 \% \\
\text { closed) with } \\
\text { central vein } \\
\text { occlusion }\end{array}$ & $\begin{array}{l}\text { R. prophylactic } \\
\text { peripheral iri- } \\
\text { dectomy } 4 \text { months } \\
\text { ago } \\
\text { L. sector iridectomy } \\
4 \text { months ago. } \\
\text { No drops }\end{array}$ \\
\hline 6 & 68 & $\mathbf{M}$ & $\begin{array}{l}\text { R. and L. ocular } \\
\text { hypertension }\end{array}$ & Nil \\
\hline 7 & 68 & $\mathbf{F}$ & $\begin{array}{l}\text { R. and L. ocular } \\
\text { hypertension }\end{array}$ & $\begin{array}{l}\text { Atenolol eye drops } \\
4 \% \text {, daily } 4 \times, \\
\text { R. and } L \text {. }\end{array}$ \\
\hline 8 & 79 & $\mathbf{F}$ & $\begin{array}{l}\text { R. Ocular hyper- } \\
\text { tension } \\
\text { L. open-angle } \\
\text { glaucoma }\end{array}$ & Nil \\
\hline
\end{tabular}

study day. The trial was thus double-masked, neither tonometrist nor patients being aware of treatment assignment at any time during the study.

The randomisation scheme, giving the treatment assignments for each patient, was devised to ensure that 4 of the 8 patients received guttae atenolol $4 \%$ on their first study day. The remaining 4 patients were given guttae saline $0.9 \%$. On the second study day treatments were crossed over. The order of treatment for the first patient who entered the study was transposed, however. This patient had been assigned saline on day 1 , but the bottle was empty and the tonometrist was ignorant as to which preparation had evaporated. Both to avoid inconvenience to the patient and violation of the masking, the assignment for day 2 was used. As a result of the transposition the balance of the design altered,
5 patients receiving guttae atenolol $4 \%$ as day 1 treatment instead of 4 as planned. The order in which treatments were administered does not appear to influence the magnitude of response, however, and so the departure is unlikely to be serious.

\section{Results}

Fig. 1 shows the graphs of tonometry on the first tonometrised eyes in the 8 patients (right eye for all but patient 5).

There is a consistent advantage in favour of the atenolol-treated eye compared with the salinetreated eye (median $5.6 \mathrm{mmHg}$, range 3.2 to 13.2 $\mathrm{mmHg}, \mathrm{P}<0.05$, Wilcoxon matched pairs signed rank test).

Table 2 summarises the response to atenolol by first and second tonometrised eyes in the study patients.

It may be interesting to note that in 6 out of 7 patients the response to atenolol was lower in the patient's second treated than first treated eye. This observation is not statistically significant.

\section{Discussion}

Although these 1-day observations have shown a statistically significant decrease in ocular tension produced by guttae atenolol $4 \%$ when compared with guttae saline $0.9 \%$, much more information is required before such drops should be used regularly in the treatment of glaucoma. However, so far as they go, the results are encouraging. Investigations on the following points should be done:

(a) Duration of action. The interval between drops was arbitrary and based on a previous study (Elliot et al., 1975), which suggested a duration of action of the systemic drug of 7 hours. A separate study would be useful to elucidate time taken for the hypotensive effect to disappear (i) after 1 dose and (ii) after use of the drops for several months.

(b) Effectivity over time. It is quite likely that the effectivity of the drops will be greater during the first 12 hours than subsequently. We have obtained information on 2 patients in this regard. After a month on guttae atenolol $4 \%$ right and left alone, patient No. 7 was admitted to hospital on day 1, and tonometrised at $0930,1230,1430$, and 1630 on days 2 to 5 and discharged on day 6 . On day 2 she was given guttae atenolol $4 \%$ right and left at 0800,1200 , and 1600 but this was changed (unknown to the patient and tonometrist) to guttae saline $0.9 \%$ right and left on days 3,4 , and 5 at the same times of day.

The results are shown in Fig. 2. There seems to be a carry-over effect of atenolol for 24 hours, then 

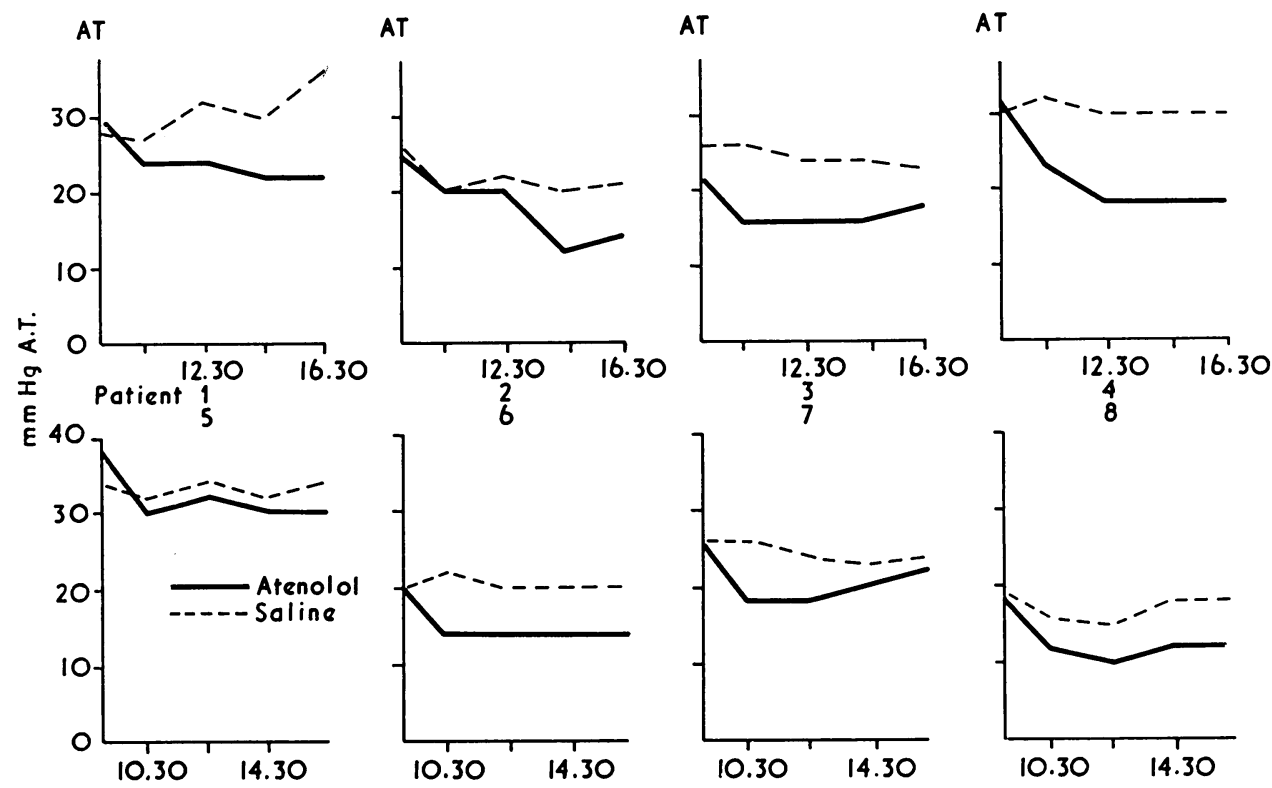

Fig. 1 Applanation tonometry in the first tonometrised eyes (right eye for all except patient 5) (a) after 1 dose of guttae atenolol $4 \%$ just after a reference tonometry at 0900 and (b) after 1 dose of guttae saline $0.9 \%$

Table 2 Response to atenolol drops (after allowance for 'response' to saline drops on control day)

\begin{tabular}{|c|c|c|c|c|}
\hline \multirow{2}{*}{$\begin{array}{l}\text { Response to } \\
\text { atenolol }\end{array}$} & \multicolumn{2}{|c|}{$\begin{array}{l}\text { First tonometrised eye } \\
n=8 \text { patients }(\mathrm{mm} \mathrm{Hg})\end{array}$} & \multicolumn{2}{|c|}{$\begin{array}{l}\text { Second tonometrised eye } \\
n=7 \text { patients }(\mathrm{mmHg})\end{array}$} \\
\hline & Median & Range & Median & Range \\
\hline Overall & $5 \cdot 6$ & $3 \cdot 2$ to $13 \cdot 2$ & $3 \cdot 5$ & 0.8 to 10.8 \\
\hline $\begin{array}{r}\text { At } 1630 \\
\text { hours }\end{array}$ & 6 & 1 to 16 & 2 & -2 to 10 \\
\hline
\end{tabular}

*The right cornea of 1 of the 8 patients was excluded from tonometry.

Overall response to atenolol $=$ mean diurnal fall in pressure on atenolol - mean diurnal fall on saline (within patient).

Mean diurnal fall in ocular tension = tension at 0900 hours - mean tension at $1030,1230,1430,1630$ hours.

The fall in pressure was significant $(P<0.05)$ in both first tonometrised and second tonometrised eyes to a Wilcoxon Matched Pairs Rank Test.

some rise during the second day, and a further rise almost to the pretreatment level on the third day.

A second patient (No. 4) had guttae atenolol 4\% for 2 months, was admitted on day 1, had tonometry on days $2,3,4,5$, and 8 at the same time as the other patient and was discharged on day 9. This time, in order to keep 1 eye as a control and to 'mask' the tonometrist more effectively, saline $0.9 \%$ was substituted for atenolol $4 \%$ in 1 eye only, the left. The change-over time, day 3 , was unknown to patient and tonometrist (see Fig. 3). The pressure in the left eye (saline) gradually rises towards that in the right (atenolol), although the latter may also be tending to rise.

A much larger series would be required to be convincing, but there is an indication that the hypotensive effect after some weeks is less than in the first 12 hours. On the other hand, a longer period of tonometry after withdrawal of atenolol might have shown a greater rise of pressure, indicating a greater effectivity of this new drug after time than these patients show-unless a rebound effect occurred

\section{CONCENTRATION OF ATENOLOL}

Our choice of $4 \%$ was rather arbitrary. A doseresponse study would be useful.

\section{COMBINATION WITH OTHER DRUGS}

We consider that atenolol is likely to be given along with other drugs and not alone, if it will have a place at all in the treatment of glaucoma. We suggest, however, that even if the response to atenolol when combined with other drugs is less than its solitary effect it may well be therapeutically useful-it lacks the unpleasant side-effects of the miotics. Separate studies are required to assess whether its effect will be additive to ( \pm adjuvant effect) or possibly subtractive from, say, pilocarpine, phospholine iodide, adrenaline, and acetazolamide. 


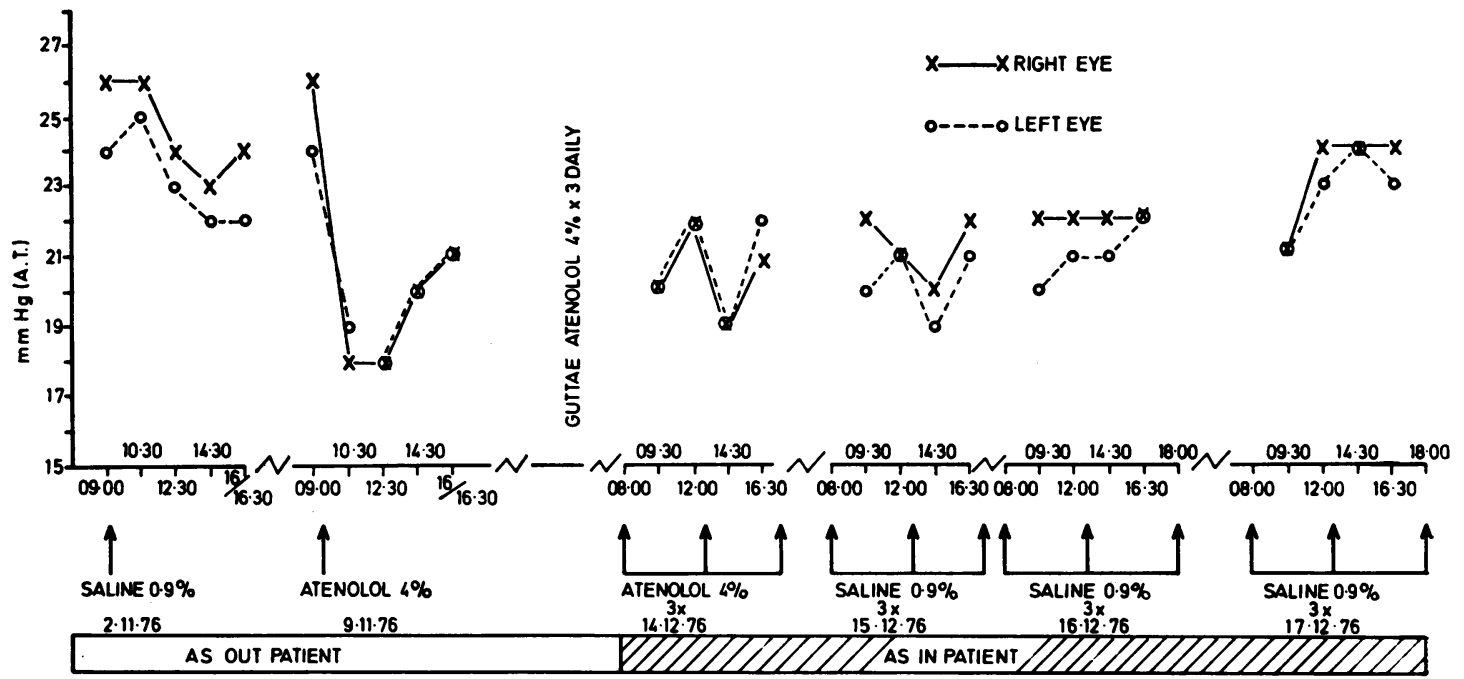

Fig. 2 Patient 7. Note dramatic fall in pressure produced by guttae atenolol $4 \%$ right and left on 9 November 1976 as outpatient compared with saline $0.9 \%$ on 2 November 1976. The effect seems still maintained on 14 December 1976. Substitution of saline $0.9 \%$ in both eyes shows a definite rise of pressure of around $3 \mathrm{mmHg}$ on the third day (? carry-over effect in the first day)

Its effect in combination with guttae adrenaline will be particularly interesting since there may well be a positive interaction, i.e., a more than additive effect. Since it is known that $\alpha$-stimulation (e.g., Pollack and Rossi, 1975) and $\beta_{2}$-stimulation
(Patterson and Paterson, 1971) reduce ocular tension, and we now know that $\beta_{1}$-blockade reduces tension, the $\beta_{1}$-stimulation produced by adrenaline may well be reducing the latter's efficacy-so we suspect that pretreatment with atenolol may be necessary to

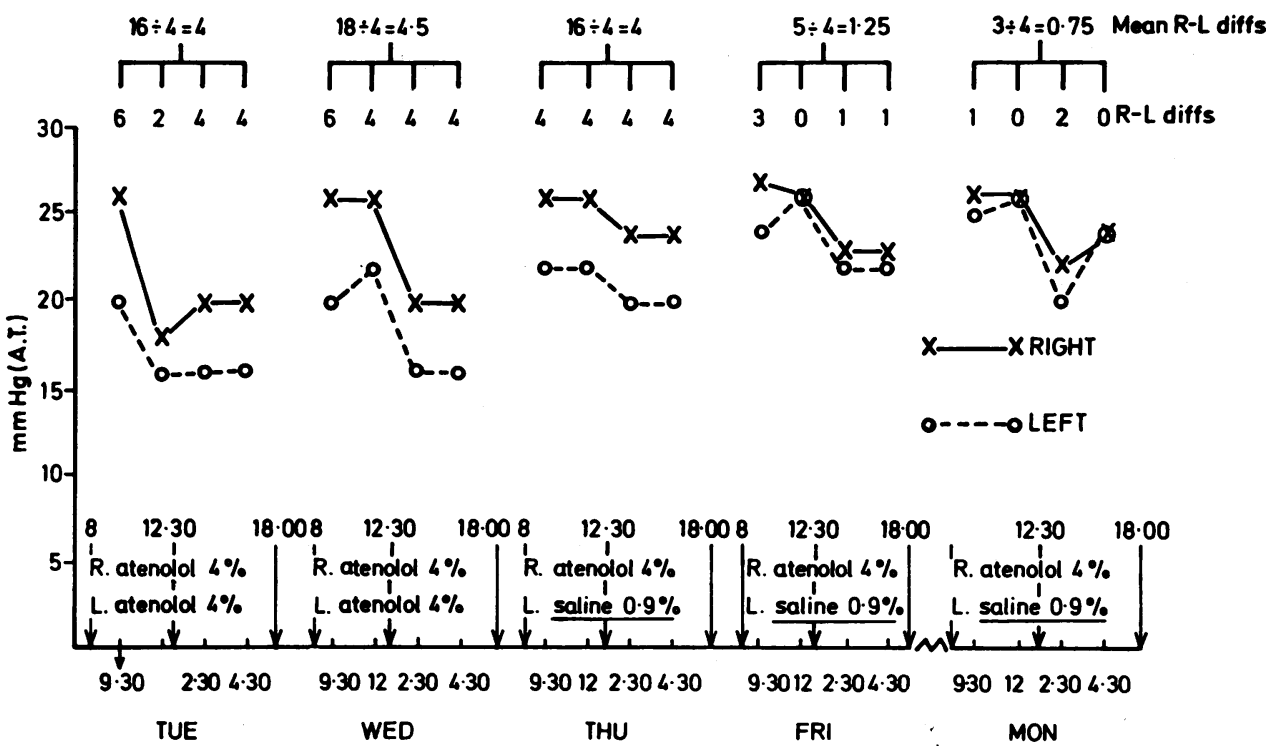

Fig. 3 Patient 4, treated for the 2 previous months with atenolol $4 \%$ right and left. On the fifth day following substitution of saline $0.9 \%$ for atenolol $4 \%$ in the left eye only (the right continuing on atenolol $4 \%$ ) the mean right and left difference becomes $0.75 \mathrm{mmHg}$ compared with 4 and 4.5 on the first 2 days when atenolol $4 \%$ was given to both eyes 
achieve this adjuvant effect. Investigations have been started to elucidate this and also to compare the efficacy of guttae adrenaline and guttae atenolol. A more direct proof of $\beta_{1}$-stimulation's hypothesised ocular hypertensive activity would be to test the effect of guttae dobutamine, if that were practicable.

On the other hand, we suspect that pilocarpine may reduce atenolol's effect (unless the latter is given before the first dose of pilocarpine each morning). We guess that atenolol may cause its fall in pressure by reducing the amount of secretion of aqueous humour: presumably it may gain access to the ciliary epithelium mainly by diffusion through the ciliary muscle. That route would be blocked by the muscle spasm produced by pilocarpine; hence the expectation of interference with atenolol's effect. The necessary investigations are planned.

\section{TOXICITY}

Many patients will have to be treated for years before we can be confident that the many possible toxic side-effects do not arise, e.g., cataract, allergy, corneal changes. However, so far, in a series of about 6 patients treated for 3 to 4 months the drops have proved comfortable, non-irritant, and non-allergic.
We are grateful to ICI (Pharmaceuticals) Ltd for supplies of guttae atenolol $4 \%$ (Tenormin) and a research grant, and to Dr A. Rushton for much helpful discussion.

\section{References}

Barrett, A. M., Carter, J., Fitzgerald, J. D., Hull, R., and Le Count, D. (1973). British Journal of Pharmacology, 48, 340.

Bonomi, L., and Steindler, P. (1975). British Journal of Ophthalmology, 59, 301.

Elliot, M. J., Cullen, P. M., and Phillips, C. I. (1975). British Journal of Ophthalmology, 59, 296.

Musini, A., Fabbri, B., Bergamaschi, M., Mandelli, V., and Shanks, R. G. (1971). American Journal of Ophthalmology, 72, 773.

Paterson, G. D., and Paterson, G. (1971). Postgraduate Medical Journal, Supplement, 47, 122.

Phillips, C. I., Macdonald, M., Gore, S. M., and Cullen, P. M. (1976). British Medical Journal, $2,1448$.

Pollack, I. P., and Rossi, H. (1975). Archives of Ophthalmology, 93, 173-177.

Vale, J., Gibbs, A. C. C., and Phillips, C. I. (1972). British Journal of Ophthalmology, 56, 770-775.

Vale, J., and Phillips, C. I. (1973). British Journal of Ophthalmology, 57, 210.

Wettrell, K., and Pandolfi, M. (1975). Experimental Eye Research, 21, 451-456. 